\title{
Construction study of body style with measurement indicates
}

\begin{abstract}
Since there are highly diversified body styles, the garment sample is affected by different sizes of the body. Therefore, understanding the body style and mastering the measurement of it is one of the important things for fashion design beginners to achieve when learning to make a garment sample. This study is aimed at developing the body style's human body measurement indicators and discusses the measurement which identifies different body styles. The study used a sample of 270 female students at some university in Taiwan's southern areas. It also adopted the static human body measurement method to measure 29 important body sizes in terms of determining the body style. After the classification of body styles based on clustering analysis, focus group interviews were taken to compare the characteristic body sizes of body styles, and the fuzzy Delphi method was adopted to identify the important measurement items for determining a body style and therefore, to set up the measurement indicators for the body style. The study result can help fashion design beginners determine body styles and produce garment samples that are more suitable for the body.
\end{abstract}

Keywords: body style, measurement indicators, focus group interviews, cluster analysis
Volume 2 Issue 2 - 2017

\author{
Wen-Hsuan Chien, Chia-Hsu Lin \\ Department of Living Services Industry, Tainan University of \\ Technology, Taiwan
}

Correspondence: Chia-Hsu Lin, Department of Living Services Industry, Tainan University of Technology, Taiwan, Email t30040@mail.tut.edu.tw

Received: March 26, 2017| Published: June 26, 2017

\section{Introduction}

As their living standard increases, people are becoming more and more demanding in terms of ergonomics and comfort. Consequently, a great variety of clothes that emphasize on ergonomics have come into the market to satisfy consumers' need for good quality and comfortable clothes. ${ }^{1}$ To meet consumers' requirement for clothing comfort and fitness, it is important for fashion design beginners to properly understand the body style and have a clear idea about the related crucial measurement items. The features of the human body's shape and the ratios of all parts of the body reflect the style of the human body. People have different opinions about the definition of the body style. The human body style is distinct because of different races, living environments, ages, sexes and time. ${ }^{2-5}$ Literature and advanced countries' survey results have shown that the time interval of change of the human body's sizes has been shortened from 10years to 3-5years, demonstrating obvious differences in the body style.,

The body style and the measurement of the human body are significant for fashion design beginners to learn in the studies of make a garment sample. Many previous studies on the body style often only carried out the analysis of the body style and the classification of body sizes. ${ }^{8-10}$ Research on the classification of the body style from the perspective of clothing production is uncommon. However, students currently need to know the relationship between different body styles and body sizes in order to make a garment sample quickly and properly. Generally, for vocational or university students of fashion, if they are able to determine the body style first, they will achieve good result quickly, increase confidence in their studies and strengthen their interest in clothing.

Therefore, the purpose of this study is to discuss the body size measurement that affects the classification of the body style and to find out the items that decide the classification of body sizes. By finding out essential body size measurement items, the study result can offer a method to experts for determining the differences in the body style, help fashion design beginner quickly learn the essential items for determining the body style which serves as the basis for making a garment sample, and increase students' confidence in mastering this skill.

\section{Research method}

\section{Research subjects}

The research subjects of the study were a total of 270 female students who were randomly selected and studying at the first term of 2006 academic year at a university in southern regions. The survey began on 7 November 2016 and ended on 23 November 2016.

\section{Data collection}

The major five measurement instruments of the study are a height measure, an electronic balance, a measuring tape, a leather ruler and a self-made $\mathrm{F}$ ruler. The items which each instrument measures are shown as follows:

a. The height measure: the height of the research subject

b. The electronic balance: the weight of the research subject

c. The leather ruler: A total of 21 items (the heights and widths of the research subject): chest width, breast circumference, shoulder width, back width, armpit width, upper arm circumference, frontal wrist maximum circumference, wrist circumference, sleeve length, frontal sleeve length, back sleeve length, waist circumference, abdominal circumference, hip circumference, thigh circumference, knee width, calf circumference, minimum calf circumference, total length, trouser length, and body rise. 
d. The F ruler: A total of six items: frontal breast width, side breast width, frontal waist width, side waist width, frontal hip width, and side hip width.

\section{Data analysis}

Based on its research purpose, this study used the statistics software SPSS (version 22.0) to analyze data (correlation analysis and clustering analysis). After the classification of the body style was made based on clustering analysis, focus group interviews compared the characteristic body sizes of a body style and finally, the fuzzy Delphi method was used to determine the important measurement items for the classification of the body style and to develop body measurement indicators for the body style.

\section{Research results}

\section{The relevant analysis results}

The correlation between the two measurement items were analyzed with the statistics software SPSS (version 22.0) and the result shows:

A. The ultra-highly correlated items with a coefficient of over 0.8 are listed as follows: breast circumference and frontal chest wi$\mathrm{dth}$, side breast width (thickness), weight, waist circumference; upper arm circumference and elbow circumference, waist circumference, hip circumference; elbow circumference and upper arm circumference, wrist circumference, hip circumference, weight; weight and breast circumference, elbow circumference, waist circumference, hip circumference, thigh circumference, calf circumference; waist circumference and breast circumference, upper arm circumference, weight, hip circumference, frontal waist width, side waist width (thickness); hip circumference and upper arm circumference, elbow circumference, weight, waist circumference, thigh circumference, calf circumference, frontal hip width, side hip width, and so on
B. Breast circumference and back width (0.664), armpit width (0.665), upper arm circumference (0.790), elbow circumference $(0.775)$, wrist circumference $(0.654)$, frontal breast width (0.819), side breast width $(0.858)$, waist circumference $(0.817)$, abdominal circumference (0.680), hip circumference $(0.784)$, thigh circumference $(0.749)$, knee circumference $(0.662)$, calf circumference $(0.736)$, frontal waist width $(0.777)$, side waist width (0.773), frontal hip width (0.667), side hip width (0.730), all have high correlation with a coefficient of over 0.6 .

C. According to the researcher's observations, the shoulder slope and other measurement items show extremely low correlation. As the shoulder slope is an independent measurement item, it is not affected by body sizes.

\section{The results based on clustering analysis and fuzzy del- phi method}

At this stage, the clustering analysis was carried out based on the above correlation coefficients to determine how to classify each research subject's body style. Then, representatives were selected from each body style cluster and characteristic differences of the body style clusters were compared. Aimed to gain the best clustering analysis results, clusters were formed based on repeated tests using Wards' clustering analysis method and the results were demonstrated with a dendrogram. After selections, 4 clusters were finally confirmed and shown in Table 1 . There were 6 experts invited to have a focus group interviews on the representative research subjects of each body style cluster to select the important measurement items of the body style. The result of which is shown in Table 1. In the end, based on the consensus of the experts and fuzzy Delphi method, 5 the important measurement items for determining body styles were confirmed. The measurement items with De-fuzzy number less than 6.5 were deleted. Then, the body measurement indicators of the body style were established. The results are shown in Table 2.

Table I The Features of the Body Style

\begin{tabular}{ll}
\hline Body style & Expert's opinion \\
\hline Style A & $\begin{array}{l}\text { Expert A: Sloping Shoulders,Big Breast, Extremely Slim Waist, Big Hip Circumference, Well-developed Thigh, Fatty } \\
\text { Inner Middle Leg, Obvious Calf, Relatively Fatty Calf, Short Upper Body \& Long Lower Body, Obvious Side Body } \\
\text { Figure }\end{array}$
\end{tabular}

Expert B: Droop Shoulders, Perky Breast, Slightly Thick Waist, Without belly Fat, Big Hip ,Circumference, Bigger Body Rise, Normal Shin, Thick Arm, Round Body, Long Upper Body \& Short Lower Body

Expert C:Narrow Shoulders,Big Hip, Erected Back, Droop Shoulder, Slightly Fat with Round Body, Big and Perky Breast, Extremely Slim Side Waist, Big Frontal Hip, Big and Round Hip, Well-developed Thigh, Even Fat Legs, Thick and Fatty Arm, Short Upper Body \& Long Lower Body

Expert D: Small Shoulder, Droop Shoulders,Big Breast, Big Hip, Strong Side Thigh, Thick and Strong Shin, Thick Arm

Expert E: Small Shoulders, Sloping Shoulders, Perky Breast, Relatively Big Hip, Perky Hip, Short Upper Body

Expert F: Big Breast, Big Hip Circumference, Large Leg Circumference, Big Arm Circumference, Longer Front Body, Round Body 
Table Continued..
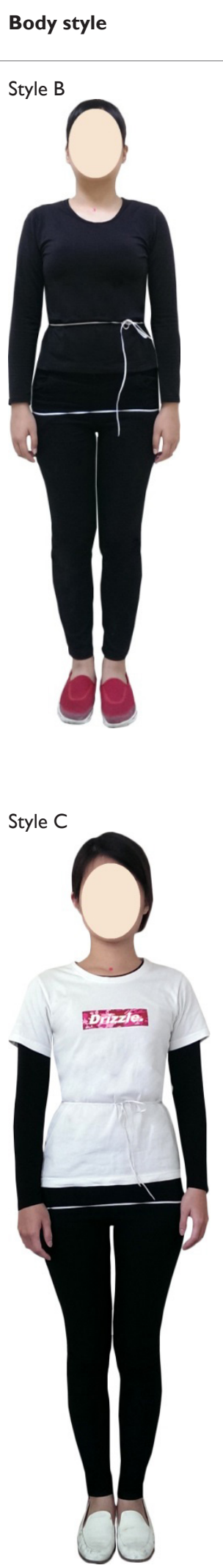

\section{Expert's opinion}

Expert A: Relatively Flat Shoulder, Small Breast, Sharp Bend at the Waist, With Belly Fat, Big Abdominal Circumference, Big Hip, Perky Hip, Well-developed Thigh, Fatty Inner Middle Leg, Prominence on the Back

Expert B: Flat Shoulder, Sharp Bend at the Waist, Slim Waist, Small Projecting Belly, Perky Hip, Even Thigh, Normal Arm Circumference,Hunchback,Enveloped Background Body

Expert C: Flat Shoulder, Relatively Fatty Back, Well-developed Breast, Round Body,S Shape Back, Projecting Side Thigh Muscle, Slightly Projecting Belly, Short Upper, Body and Long, Lower Body, Projecting and Strong Hip, Perky Hip, With Calf, Slightly Hunched, Median Height, Relatively Erected Shoulders

Expert D: Enveloped Back, Small Bra Cup, Low Breast Points, Slim Waist, Slightly Projecting Belly, Projecting Side Thigh Muscle, Slight Hunchback

Expert E: Flat Shoulder,Without Waist Shape, Forward Belly, Projecting Hip, Hip Projecting backward, Thick Thigh, Fleshy Arm, Tall and Fat, Hunchback

Expert F: Relatively Flat Shoulder, Small Waist-to-Hip Ratio, Hip Projecting backward, Big Leg Circumference

Expert A: Small Breast, Slim Waist, Relatively Large Belly, Small Hip Circumference, Slender Leg, Small Leg Circumference,Well-proportioned,Small Waist-to-Hip Ratio, Long upper body, Normal lower body

Expert B: Normal Shoulder, Small Breast, Big Hip, Droop Hip, Flat Hip, Short Shin, Erected Back, Flat Body, Long Upper Body and Short Lower Body

Expert C: Sloping Shoulder, Flat Hip,(Erected Back) Normal,Thin,Not tall,Well-proportioned,Erected Back, Flat Body

Expert D: Flat Shoulder, Small Breast Cup, Good Breast Position, Slender Thigh, Even Shin, Well-proportioned

Expert E: High BP Point, Obvious Waist Shape, Flat Hip, Straight Back, Flat Body

Expert F: Small Shoulder Width, Small Breast, Flat Hip, Small Leg Circumference, Flat Hip, Small Arm Circumference 
Table Continued.

\section{Body style}

Style D

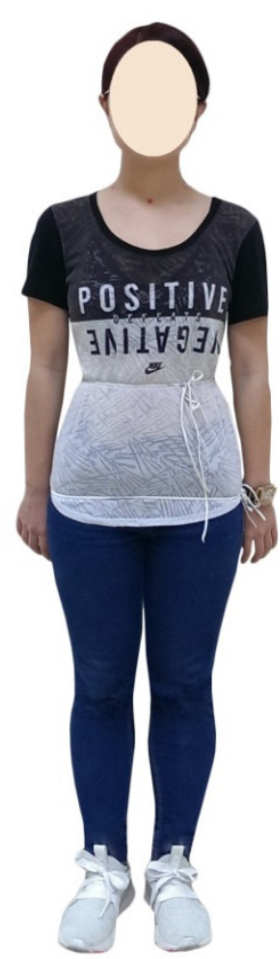

\section{Expert's opinion}

Expert A: Normal Breast Size, Small Waist, Fleshy Hip, Relatively Large Hip Circumference, Sporty Thigh, Obvious Middle Thigh Circumference, Obvious Projecting Calf, Big Calf,Short,Short Upper Body, Obvious Figure

Expert B:Wide Shoulder, Normally Droop Shoulder, Small Breast, Small Waist, Droop Hip, Radish-like Legs, Flat Body,Hourglass-shaped,O-leg,Slight Hunchback

Expert C: Higher Right Shoulder and Lower Left Shoulder, Short Upper Body and Long Lower Body, Normally Sloping Shoulder, Shoulder Width Same as Hip Width, Slim Waist, Round and Projecting Hip, Proportioned Large Hip Circumference, Well-developed Thigh, Short and Thin, Round Body, Flat Upper Body, Round Lower Body, Flat Foot

Expert D:Wide Shoulder, Flat Shoulder, Small Breast Cup, Well-developed Thigh, Sporty Middle Thigh Circumference, Strong Shin, Slim

Expert E:Wide Shoulder, Small Breast, Obvious Waist Shape,Without Belly Fat

Expert F: Small Breast, Droop Hip, Large Thigh Circumference, Large Calf Circumference

Table 2 The Results Based on Fuzzy Delphi Method

\begin{tabular}{|c|c|c|c|c|}
\hline Number & Measurement item & Triangular fuzzy number & De-fuzzy number & Delete \\
\hline I & Shoulder Width & $(6,8.21,9)$ & 7.7 & --- \\
\hline 2 & Shoulder slope & $(4,7.55,9)$ & 6.8 & --- \\
\hline 3 & Breast Circumference & $(6,8.60,9)$ & 7.8 & --- \\
\hline 4 & Side Breast Width & $(4,7.55,9)$ & 6.8 & --- \\
\hline 5 & Front Breast Width & $(2,6.23,9)$ & 5.7 & Delete \\
\hline 6 & Waist Circumference & $(6,8.60,9)$ & 7.8 & --- \\
\hline 7 & Side Waist Width & $(4,7.38,9)$ & 6.8 & --- \\
\hline 8 & Front Waist Width & $(2,6.18,9)$ & 5.7 & Delete \\
\hline 9 & Abdominal Circumference & $(6,8.21,9)$ & 7.7 & --- \\
\hline 10 & Hip Circumference & $(8,9.00,9)$ & 8.6 & --- \\
\hline II & Waist Length & $(4,6.79,9)$ & 6.6 & --- \\
\hline 12 & Knee Circumference & $(2,4.80,9)$ & 5.2 & Delete \\
\hline 13 & Thigh Circumference & $(6,8.60,9)$ & 7.8 & --- \\
\hline 14 & Calf Circumference & $(4,7.21,9)$ & 6.7 & --- \\
\hline 15 & Ankle Circumference & $(I, 3.8 I, 9)$ & 4.6 & Delete \\
\hline 16 & Upper Arm Circumference & $(6,7.85,9)$ & 7.6 & --- \\
\hline 17 & Elbow Circumference & $(2,4.81,9)$ & 5.2 & Delete \\
\hline 18 & wrist Circumference & $(I, 3.14,9)$ & 4.3 & Delete \\
\hline
\end{tabular}


Table Continued..

\begin{tabular}{lllll}
\hline Number & Measurement item & Triangular fuzzy number & De-fuzzy number & Delete \\
\hline 19 & Arm Base Circumference & $(2,5.95,9)$ & 5.6 & Delete \\
20 & Height & $(4,7.67,9)$ & 6.9 & -- \\
\hline 21 & Cervical Vertebra Height & $(1,2.68,5)$ & 3.2 & Delete \\
22 & Weight & $(5,7.16,9)$ & 6.7 & -- \\
23 & Front Body Length & $(7,7.85,9)$ & 7.6 & --- \\
24 & Back Body Length & $(7,7.85,9)$ & 7.6 & -- \\
25 & Chest Width & $(5,7.00,9)$ & 6.6 & --- \\
26 & Back Width & $(5,7.00,9)$ & 6.6 & --- \\
27 & Frontal Hip Width & $(5,7.38,9)$ & 6.8 & --- \\
28 & Side Hip Width & $(5,7.73,9)$ & 6.9 & --- \\
29 & Waistband Height & $(7,7.85,9)$ & 7.6 & -- \\
\hline
\end{tabular}

Note The measurement items with De-fuzzy number less than 6.5 were deleted.

Table 3 Body Style Measurement Indicators

\begin{tabular}{ll}
\hline Perspectives & Item \\
\hline Appearance & Height, Weight, Shoulder slope \\
Frontal Width & $\begin{array}{l}\text { Shoulder Width, Chest Width, Back Width, } \\
\text { Frontal Hip Width }\end{array}$ \\
Side Width & $\begin{array}{l}\text { Side Breast Width, Side Waist Width, Side Hip } \\
\text { Width } \\
\text { Body Circumference }\end{array}$ \\
$\begin{array}{l}\text { Breast Circumference,Waist Circumference, } \\
\text { Abdominal Circumference, Hip Circumference } \\
\text { Limb Circumference }\end{array}$ & $\begin{array}{l}\text { Thigh Circumference, Calf Circumference, } \\
\text { Upper Arm Circumference }\end{array}$ \\
Body Length & $\begin{array}{l}\text { Front Body Length, Back Body Length, Waist } \\
\text { Length,Waistband Height }\end{array}$ \\
\hline
\end{tabular}

\section{Conclusion}

The study used correlation analysis to explore the correlation between body sizes, developed 4 body styles based on the clustering analysis of an sample of 270 people, selected the characteristics of the 4 body styles based on experts' opinion and consensus, and set up the measurement indicators of the body style. As shown in Table 3, there are 5 perspectives: appearance, frontal width, side width, body circumference, limb circumference, body length; There are 21 items: height, weight, shoulder slope, shoulder width, chest width, back width, frontal hip width, side breast width, side waist width, side hip width, breast circumference, waist circumference, hip circumference, circumference width, calf circumference, upper arm circumference, front body length, back body length, waist length, waistband height.

\section{Acknowledgments}

None.

\section{Conflict of interest}

Author declares there is no conflict of interest in publishing the article.

\section{References}

1. Chiu LW, Lee KC, Chang WY, et al. The Influence Cool Fabrics on the Physiological Varieties of Human Body. Journal of the Hwa Gang Textile. 2008;16(2):166-175.

2. Camp S. Black Is Beautiful: An American History. J Southern History. 2015;81(3):675-690.

3. Salk RH, Engeln-Maddox R. If you're fat then I'm humongous: Frequency, content, and impact of fat talk among college women. Psychology of Women Quarterly. 2011;35:18-25.

4. Sara B, James R. Measuring masculine body ideal distress: Development of a measure. International Journal of Men's Health. 2004;3(1):1-10.

5. Hsu SS. Human Factors Engineering. Yongchi Culture. 1991.

6. Martin Brett AS, Xavier R. How do consumers react to physically larger models? Effects of model body size, weight control beliefs and product type on evaluations and body perceptions. Journal of Strategic Marketing. 2010;8(6):489-501.

7. Hseuh HC. Investigating Basic Bodice Block Construction Using Anthropometric Body Measurements-A Case Study Based upon Hsiu-Chen Basic Bodice Block. Fu-Jen Catholic University, Taiwan; 2004.

8. Cullari S, Vosburgh M, Shotwell A, et al. Body-image assessment: A review and evaluation of a new computer-aided measurement technique. North American Journal of Psychology. 2002;4(2):221-232.

9. Al Sabbah H, Vereecken CA, Elgar FJ, et al. Body weight dissatisfaction and communication with parents among adolescents in 24 countries: international cross-sectional survey. BMC Public Health. 2009;9:52.

10. Tsai CC. Application of three-dimensional space human measurement data in the establishment of clothing size classification system. National Tsing Hua University, Taiwan; 2000. 
